\title{
Distributed Knowledge Management in Health Care Administration
}

\author{
Holm Larsen, Michael; Pedersen, Mogens Kühn
}

\author{
Document Version \\ Final published version \\ Published in: \\ Proceedings of the 34th Hawaii International Conference on System Science. HICSS-34
}

DOI:

10.1109/HICSS.2001.927029

Publication date:

2001

License

CC BY-NC-ND

Citation for published version (APA):

Holm Larsen, M., \& Pedersen, M. K. (2001). Distributed Knowledge Management in Health Care Administration. In R. H. Sprague, Jr. (Ed.), Proceedings of the 34th Hawaii International Conference on System Science. HICSS-34 IEEE. https://doi.org/10.1109/HICSS.2001.927029

Link to publication in CBS Research Portal

\section{General rights}

Copyright and moral rights for the publications made accessible in the public portal are retained by the authors and/or other copyright owners and it is a condition of accessing publications that users recognise and abide by the legal requirements associated with these rights.

\section{Take down policy}

If you believe that this document breaches copyright please contact us (research.lib@cbs.dk) providing details, and we will remove access to the work immediately and investigate your claim. 


\title{
Distributed Knowledge Management in Health Care Administration
}

\author{
Michael Holm Larsen and Mogens Kühn Pedersen \\ Department of Informatics, Copenhagen Business School \\ E-mail: \{mhl,mk\}.inf@cbs.dk
}

\begin{abstract}
The paper addresses the electronic commerce application field of Health Care Administration. Models for knowledge distribution is a rare commodity in the Health Care Administration. Distributed Knowledge Management (DKM) is a concept that originated as an abstraction of a business model prepared for the mechanical and agricultural industry but holds promises for a more general use. The contribution of this paper is to suggest a new business model based on DKM and show the relevance and applicability of this concept in a totally new context of the Health Care Administration.
\end{abstract}

\section{Introduction}

As a comprehensive documentation of individual patient records is a prerequisite for efficiency improvements in a fragmented medical value chain, the health care industry needs effective means to manage data as well as information and knowledge. The purpose of introducing an abstract model for knowledge management is to ensure the problem is not only solved from a micro perspective with bilateral communications, but is brought into a macro perspective with structured multilateral business relations. Apart from the perspective of structuring business relations, an abstract model also may offer the opportunity to balance quality care with low costs efforts.

These relations may be supported by information and communication technologies, which throughout the last decade have been more and more accepted in the health care industry and sector. Information and communication networks extend the reach and range of the firm's business opportunities [1]. The information technologies of networks radically challenge management to consider the information separability of their major business processes [2]. Thus we are moving from business process redesign into a business network redesign era of strategic management [3], [4], [5], [6].

The principles governing strategizing network reconfiguration cannot be found in the conception of knowledge management as purely an internal business affair. Moving beyond the boundaries of the firm into the extended enterprise [7] elevates the virtual organising of business into a knowledge based strategy for a "dynamic portfolio of relationships to assemble and co-ordinate the required assets for delivering value to the customers" [8]:33. Business-to-business networks transcend the conventional image of value chains creating a complex exchange of specific information and in particular of specific knowledge [9].

We argue that health care provision and administration represents an instance of applicability of a network distributed knowledge management model (DKM). A case from the US health sector proves this right.

The model to be presented caters for knowledge relations and the specific nature of network relations while stressing decision support [10]. We argue that the exchange of asymmetric, specific knowledge in a network economy generates among all the participants a performance superior to that achieved without distributed knowledge networks.

\section{Knowledge Management: Centralised versus distributed}

This article emphasises the interorganisation perspective on knowledge management. Of a particular interest is the capability of information technology to serve human purposes using symbols that are an integrated part of knowledgeable human behaviour. Information technology in this regard is a knowledge technology that processes meaningful symbolic behaviour to manage extended economic organisations [7], [11]. Knowledge management is therefore bound to rely upon information 
technologies including networks, the technologies of processing, transmission and storage, as these continuously experience diminishing costs compared to wages and capital equipment. Distributed knowledge management contemplates issues found in network theory exploring "co-specialised assets, joint control, and collective purpose" [12]:86. These trends convergence in the question what knowledge management needs to provide for in economic organisations?

Knowledge management meant the application of information technologies first represented in the acquisition of knowledge in a knowledge repository and later represented in network models like intranet and extranet [13], [14]. The network perspective receives increasing interest in the management literature as "the future competition is not between companies, but between networks" [15]. Since the early dawn of knowledge management several developments ensued.

The centralised knowledge creation model promotes the idea of making knowledge available to the whole organisation as the purpose of knowledge management [16], [17], [18], [19], [20], [21]. Thus knowledge management (KM) faces the challenge how to ensure a dynamic updating of knowledge.

The alternative to a centralised knowledge management model, a distributed knowledge management model, generates knowledge amongst decision-makers in interdependent businesses on a continuous basis while redistributing the outcome for a time efficient knowledge use. The symmetries in knowledge and time specificity of the decision-makers ensure that knowledge creation in an actor network is an incentive compatible exchange of knowledge [22].

The centralised KM model consists in a conversion from individual, knowledge specificity into organisational, collective knowledge made available to all individuals where each individual user on an ad hoc basis converts the global knowledge into local decision support. In contrast, the distributed KM model requires another conversion. The focus is on the exchange of specific knowledge to network actors in a mutual value-adding network. Each actor appropriates information and submits enhanced information that in return becomes enhanced by other network actors at other destinations and thus return to the originator more valuable than when originated. The latter process also makes for the difference between a centralised KM system that is passive in regard to decision making and an active distributed decision support system that takes advantage of the knowledge specificity related to different actors. And finally knowledge creation in terms of knowledge specificity encompasses both tacit and explicit knowledge since the same individuals or teams that create knowledge apply it [23], [24], [25]. The emergent knowledge co-located with the actor results from acquired knowledge from the network merged with local, specific knowledge. Therefor emergent knowledge resides with the actor and does not have to cross organisational boundaries. Only specific knowledge items are passed on in the network. This accounts for the use of both explicit and tacit knowledge in the DKM model.

The distributed KM widens the scope of knowledge management by including business partners in a broader network of knowledge exchange. In particular manufacturing and service suppliers in customer support knowledge may take advantage of the Internet by moving knowledge beyond organisational boundaries [19], [26], [8]. The supply chain attracted attention with its scope for increase of overall efficiency [27]. The linear model of a knowledge flow of the demands of customers to dealers and distributors though did not transform into value-added knowledge before considering the advantage from using the World Wide Web using rich information representations.

Today, the distinction between knowledge management in manufacturing and in professional services may seem to be overridden by the experience of knowledge management projects crossing previously relevant lines of demarcation [28], [29], [30], [31], [32], [33], [22]. The traditional dichotomy of acquiring information either in reactive mode [34] with a specific decision to make or in proactive mode to scan and monitor the environment to detect problems requires different decision management. Between the two we find a network of interdependent decision-makers all acting on information specificity that derives from knowledge specificity and time specificity [9].

The rise of knowledge management should be tempered by the concomitant rise of decision support systems, though in a new framework, viz. the distributed knowledge management. The model of supply chain management relates a significant share of all trade to opportunities of knowledge management for efficiency purposes thus representing a significant part of all business models. The supply chain network has been shown to benefit from information technology in the order fulfilment process [35]. Unlike previous often hypothetical discussions of virtual organisations, the supply chain network decision support system provides an illustration of a robust knowledge based structure where the knowledge exchange enhances the performance efficiency of all participating in the network. 
The attributes of distributed knowledge management therefor carry implications for a broad range of business applications.

\section{DiSTRIBUTED KNOWLEDGE MANAGEMENT}

The raison d'être of network distributed knowledge management resides in actor network role differentiation [36], [37], [38]. Originating in innovation studies the actor network concept now permeates into the economics and sociology of organising entities ('intermediaries') and actors that are defined through their relationships. The nature of flows of knowledge (the 'intermediaries') between actors in computer-based networks takes on a dimension of symmetric incentives not otherwise found. In traditional economic analysis interdependencies across several market boundaries go unaccounted, an exception is Porter's clusters [39], [40], [41], and in sociology these are abstracted into institutional categories in neglect of actors. Actor network theory allows for both autonomy and interdependence of actors in networks constructed by that which is exchanged, the intermediary, here specific knowledge taking account of each actor's specific role in the network. specificity from the point of view of transaction cost economics [45], [46], [47]. In this section this specificity is examined in more detail.

In this paper the health care industry is regarded, but before presenting and discussing the appropriateness of the model, the main elements of DKM are presented [48], [22].

\subsection{Information specificity}

Information specificity is defined as "the extent to which the value of information is restricted to its use and/or acquisition by specific individuals or during specific time periods" [9]:29. Information specificity is in two forms, knowledge and time specificity. Knowledge specificity refers to either scientific or technical knowledge or "knowledge of context, or knowledge of particular circumstances of time and place" [9]:30. If acquiring the information presupposes special training, insights etc. the information is high in knowledge specificity in acquisition. Specificity in use often follows specificity in acquisition [49]. Knowledge specificity may reside in different people or units in an organisation, called intra organisational knowledge specificity. Inter organisational

TABLE I

\section{THE SPECIFICITY OF INFORMATION}

\begin{tabular}{|c|c|c|}
\hline & $\begin{array}{c}\text { Time } \\
\text { Specificity }\end{array}$ & $\begin{array}{l}\text { Knowledge } \\
\text { Specificity }\end{array}$ \\
\hline $\begin{array}{l}\text { Specificity } \\
\text { in Acquisition }\end{array}$ & $\begin{array}{l}\text { Information that must be acquired immediately, } \\
\text { or very shortly, after it first originates or } \\
\text { becomes available }\end{array}$ & $\begin{array}{l}\text { Information that can be acquired only by } \\
\text { someone with the required specific } \\
\text { knowledge }\end{array}$ \\
\hline $\begin{array}{l}\text { Specificity } \\
\text { in Use }\end{array}$ & $\begin{array}{l}\text { Information that decreases in value unless used } \\
\text { immediately, or very shortly, after it becomes } \\
\text { available }\end{array}$ & $\begin{array}{l}\text { Information that can be effectively used } \\
\text { only by someone with the required } \\
\text { specific knowledge }\end{array}$ \\
\hline
\end{tabular}

Source: [9]:29.

In a business value chain the division of labour allocates different tasks for each actor. These tasks require specific and global knowledge in varying combinations for their completion. The resource-based view of the firm argues that for each actor compared to others in the same market the one succeeding the best in the value chain holds somewhat unique resources. The resource differential also explains the positioning in the value chain by reference to rents and quasi-rents from these resources [42], [43], [44]. The information associated with the resource-based view exhibits the characteristics of asset knowledge specificity in a network economy refers to the existence of knowledge that is specific to each single organisation in the network reflecting that division of labour follows from a high degree of specialisation.

Time specificity can be found in the dictum that the right information at the right place in the right time prevails over all other information. Time specificity in use reflects a loss of value if the information is not used immediately, whereas time specificity in acquisition refers to an event like nature of information, an example is that the registration of the size of an earthquake must take 
place at the time of the quake. This example also conveys that specificity in use may not follow from specificity in acquisition.

The information time specificity argument can been extended to business in general due to the proliferation of time-based competition [50], [51]. Competition leaves few without a sting from time pressures that are translated into information requirements equally time sensitive. In this sense much information acquires time specificity that if put aside devalues or makes the information irrelevant.

Timeliness no longer only resides with products like newspapers, flight tickets, tomatoes or sophisticated electronic products. Since timeliness is associated with business in general the time specificity of information assets achieves a much wider relevance than that of a particular product or service characteristic. Further, shorter product lifecycles due to innovation speed up and due to customisations result in frequent change in product varieties which makes necessary a careful productcustomer tracking system demanding a management response alike the timeliness claim.

Knowledge specificity traditionally plays a significant role in strategic technology collaboration for product development [52]. As more technologies become systemic the knowledge interdependencies increase in use while relying upon knowledge specificity in acquisition [53], [54]. In networks the knowledge specificity is a defining characteristic whether explained by the transaction cost economics of relational contracting due to asset specificity or explained by beneficial (knowledge) co-operation [55]. Knowledge specificity carries over into knowledge management issues of identification, storage and use.

\subsection{The actor network distributed knowledge management model}

The concept 'distributed' refers to an organisation in which activities are located to those locations or entities where it is best performed, determined for example by skills, costs or resources [56]. In our context, distributed normally also refers to independent organisations (companies) performing each their value-added activities.

In an actor network distributed model of knowledge management the acquisition of knowledge will not reside only within a single organisation. The inter organisational knowledge specificity reflects the differences in specialisation and position in the network, for instance a supply chain. In any organisation external business partners are a source of important business information. Therefore it remains a target in the establishment of a repository to convert various partner-competitor systems into partnership systems sharing relevant and timely information about the significant environment of the company. Facing increasing competition in e.g. customer response time organisations are looking for tools to update the repository at a continuous basis. Usually, when a certain threshold is reached that elicits signals calling for attention. The more the threshold information enters into daily routines the more decision support is derived. The knowledge specificity of a partner may be merged with that of another that converts the information into new specific knowledge. This knowledge fed back to the contributing partners' local applications generates new specific knowledge.

If we merge these aspects of information processing in an inclusive environment we end up with a system holding distributed knowledge repositories at the same time as showing decision support qualities due to information timeliness and relevancy to the network actors. The network makes partners' time specific knowledge available for processing along with the actor's own specific knowledge. This processing converts the actor's knowledge to a new, specific knowledge. The new specific knowledge or an item of it is passed on to another actor in the network. Also here specific knowledge received is merged with knowledge possessed forming a new, specific knowledge, items of which is passed on to another actor, eventually closing the circle as new specific knowledge arrives at the first mentioned actor. Of course, the actor that generate new knowledge items have to benefit from the received items in a non-intuitive way for the knowledge to be seen as vital to each actor's decision making.

The network distributed knowledge management process can be modelled in a data flow like the one of a public key system [57].

Beneath, find the decision process of each actor in the network and the distributed, specific knowledge passed on to the following actor. The figure represents a succession of nested knowledge creations in a distributed environment [58]. Each actor has independent, separate information management allowing for messageObjects for the exchange of specific knowledge items in the network.

In table 2 below the proposed model of a supply network decision support system based upon well-defined knowledge repositories is found. In the model we have stressed the requirements for viability, the knowledge repositories, the information exchanges required to convert localised, specific knowledge into properly converted specific knowledge entering decision making locally. 
We have outlined a simplified business structure in which the company exchanges information with a representative dealer and an end-user (customer) of its product or service banking on its product state model (PSM). To analyse the nature of the relationships we present the relationship in more detail. This is obtained if we consider a manufacturing company and the dealer as a service company whereas the end-user may be in any kind of trade. The determination of actors is meant as illustration of the model that is considered to be generally relevant in networks. For details see Larsen et al. [48], where a manufacturing company produces agricultural machines (sprayers), dealers are trading in machines and spare parts and farmers are operating the sprayers, vital in crop protection reducing crop damage and yield losses.

In the matrix below only knowledge regarding product maintenance and replacement is entered whereas business information like prices, quotes, orders, payments etc. all have been disregarded since that are standard information exchange in all businesses. In this example the business information interchange does not call upon a decision support model. adding up to a knowledge of the immediate expected demand for services and spare parts. At the same time the dealers offer this knowledge, not in terms of a large amount of data but in terms of a consolidated data, i.e. in the demand for allocated (reserved) stock and for a crisis managing stock to cope with unexpected demand.

The three actors of the supply network all hold privileged knowledge that, offered as continuous data to the other actors, make the aggregate information emerge as a new specific knowledge while being proper as decision support for each actor in his particular circumstances. The faster the information exchange cycle the more the quality of relevance is supplemented with the one of timeliness adding up to a new category, the distributed knowledge decision support.

Only by abandoning the dualistic model where the firm confronts an anonymous market does the nature of business-to-business and business-to-consumer relations emerge as complex interdependent relationships, the ground for evolving strategic knowledge management options. The firm has to be perceived in a heterogeneous, structured rather than a homogenous, environment where

TABLE ॥

\section{THE KNOWLEDGE EXChANGE MATRIX}

\begin{tabular}{|c|c|c|c|}
\hline $\begin{array}{l}\text { From: } \quad 1 \\
\text { To: }\end{array}$ & Producer & Dealer & End User \\
\hline Producer & $\begin{array}{l}\text { Internal } \\
\text { knowledge handling }\end{array}$ & $\begin{array}{l}\text { Product services knowledge } \\
\text { Stock mix according to PSM }\end{array}$ & $\begin{array}{l}\text { Self service manuals } \\
\text { On line advice } \\
\text { End-user community }\end{array}$ \\
\hline Dealer & $\begin{array}{l}\text { State of stock mix } \\
\text { Crisis management spare parts } \\
\text { stock }\end{array}$ & $\begin{array}{l}\text { Internal } \\
\text { knowledge handling }\end{array}$ & $\begin{array}{l}\text { Allocated (reserved) spare parts in } \\
\text { stock } \\
\text { Maintenance services }\end{array}$ \\
\hline End user & $\begin{array}{l}\text { Hours of product use } \\
\text { FAQs revealing usage } \\
\text { problems } \\
\text { Time critical services }\end{array}$ & $\begin{array}{l}\text { Maintenance support } \\
\text { Replacement support } \\
\text { Product support }\end{array}$ & Internal knowledge handling \\
\hline
\end{tabular}

Source: [22].

The knowledge management approach stresses source of knowledge and needs for sharing. In this model sharing is given by the nature of the relationships between the three actors of the supply network. They are truly interdependent if all parties hold specific information. That is the case if the dealer's database on customers informs about the propensities of customers to repair rather than replace parts and components, and the propensity to cater for risk amongst their customers, all identified complementors and customers represent opportunities but also challenges to the firm [27]. The coexistence of customer relations, business partners and relationships, and networks for distributed knowledge management coalesce into what Venkatraman and Henderson [8] have named the "architecture for virtual organising" stressing that these are strategic characteristics applicable to every organisation. 


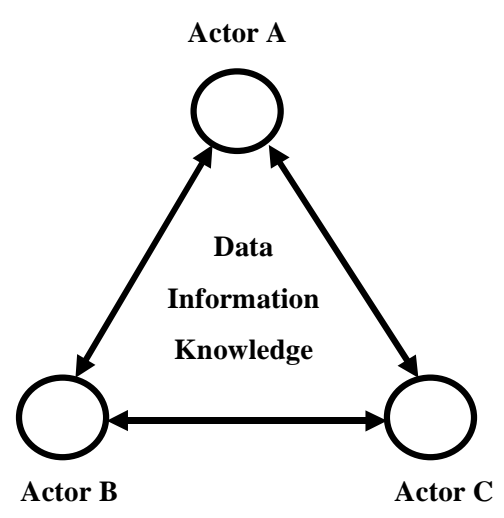

Figur 1 The distributed knowledge network model Source: [22].

\section{The Case of Arkansas Division of Medical Services}

The case study is to a large extend based on the project presentation EDS presents on their website (see eds.com) in addition to website information from Arkansas Division of Medical Services (DMS).

Arkansas DMS administrates the Medicaid program, that struggled to balance quality care with low program costs for low-income patients. The problem was that patients often went to emergency rooms and clinics for treatment. They seldom saw the same doctor more than once or twice. Therefore, doctors had to start over each time a new patient entered the clinic for treatment, which added unnecessary costs, wasted time and would furthermore potentially reduce the effectiveness of the health care.

Arkansas DMS officials recognised that doctors had the opportunities for serving patients best if they understood the medical history and treatments of each patient. As Arkansas DMS were faced with the fact that service to low-income patients under the Medicaid program increased this called for the finding of a way to forge lasting relationships between patients and primary care physicians.

Those eligible for Medicaid fall into categories such as Supplemental Security Income receivers, i.e. people older than 64, blind or disabled adults and children, participants in aid to families with dependent children, or aged, blind or disabled persons in nursing homes who meet state eligibility requirements for long-term care etc. (Medicaid, 1999). Persons who are not eligible for any of these programs may qualify for Medicaid through the Medically Needy program, depending on their incomes, resources and medical needs.

The Arkansas Medicaid Program covers 12 federally mandated services and several optional services.

With more than 415,000 potential Medicaid recipients in the state, program administrators faced three mandatory tasks for each case: confirm patient eligibility; find a primary care physician to stay with; and pay doctors, pharmacists and hospitals promptly. Failure to achieve any of these tasks could lead to untreated ailments, rising costs and reduction of the federal grants needed to fund the program.

\subsection{The AEVCS System}

Electronic Data Systems, EDS [60], designed and built an electronic business system called Automated Eligibility Verification and Claims Submission (AEVCS). The key to access the system is a photo ID card with patient data on a magnetic strip.

The AEVCS system supports the processing of eligibility-verification and claims transactions through a network of point-of-sale devices or vendor systems. Each transaction is processed in real time, and a response is returned to the submitter immediately, noting whether the transaction has been accepted by Medicaid and informing the submitter of any errors.

The AEVCS system was developed jointly by the Arkansas Department of Human Services' Division of Medical Services and EDS, Arkansas Medicaid's fiscal agent. The AEVCS system, which was piloted in 1992 and implemented throughout Arkansas in June 1993, operates at more than 2,600 provider locations.

By using sophisticated VeriFone point-of-sale devices and a nation wide packet-switching network, AEVCS lets providers determine, in real time and in one simple operation, a patient's eligibility for Medicaid. If the patient is eligible for Medicaid, AEVCS delivers an authorisation number to the provider, guaranteeing that any claim submitted for treatment on that date shall not be denied on the basis of ineligibility for benefits.

The system accepts most claim types used in the Arkansas Medicaid program including HCFA-1500 medical; UB-92 hospital inpatient and outpatient; Early and Periodic Screening, Diagnosis and Treatment (EPSDT); pharmacy; vision; dental; and long-term care claims. 


\subsection{Knowledge, Information and Data Exchange}

AEVCS can be accessed through point-of-sale devices, vendor systems, PCs and both intranet and Internet websites. Office staff members of Arkansas DMS use the websites to display state wide medical provider information and assign primary care physicians (PCP) to patients. This set up allows eligible recipients to quickly choose their PCP based on criteria important to them.

The patient's card is "swiped" through a terminal like those used with credit cards at the doctor's office. Hereby the system verifies patient eligibility and benefit use. AEVCS also confirms payment that will deposit electronically into the physician's bank account.

This flow of data, information and knowledge is collected in the table below in order to provide an overview of the communication of the business relations. exchange features specific information provided to an actor with capacity to exploit this information in actions guided by the actor's specific knowledge. The knowledge, information, and data carried by the PSM, is the core of the distributed knowledge management network.

\subsection{Technical Specifications}

The technical specifications suggested and implemented by EDS, EDI [60], was a real-time SQL*® with an online transaction processing database to support the AEVCS system, processing 17.1 million transactions per year. The AEVCS system resides on a Tandem ${ }^{\circledR}$ platform in Auburn Hills, Michigan. The Tandem platform is averaging a 20 percent capacity and uses approximately 7.4 gigabytes of disk storage. The Medicaid Management Information System (MMIS) processes paper claims and performs all "backend" claim

TABLE III

\section{THE KNOWLEDGE EXCHANGE MATRIX FOR ARKANSAS HEALTH CARE}

\begin{tabular}{|c|c|c|c|}
\hline $\begin{array}{l}\text { From: } \quad 1 \\
\text { To: }\end{array}$ & Arkansas DMS & Doctors & Patients \\
\hline $\begin{array}{l}\text { Arkansas } \\
\text { DMS }\end{array}$ & $\begin{array}{c}\text { Internal } \\
\text { knowledge handling }\end{array}$ & $\begin{array}{l}\text { Confirmation of patient } \\
\text { payment } \\
\begin{array}{l}\text { Display medical provider } \\
\text { information }\end{array}\end{array}$ & Assign primary care physicians \\
\hline Doctors & $\begin{array}{l}\text { Verify patient eligibility and } \\
\text { benefit use }\end{array}$ & Internal knowledge handling & Care, treatment, and advice \\
\hline Patients & $\begin{array}{l}\text { Request for payment status } \\
\text { information }\end{array}$ & $\begin{array}{l}\text { Patient medical history and } \\
\text { treatment (patient card) }\end{array}$ & Internal knowledge handling \\
\hline
\end{tabular}

Compared to the knowledge exchange model in previous studies, the state model of this study is the patient medical history and treatment record. Hence, in stead of speaking about a Product State Model, we might in this case speak about another kind of PSM, i.e. a People State Model. The actors holding resources relevant to the "people state model" are health service providers, i.e. primary care physicians, hospitals, dentists, pharmacies etc. as well as the agency paying for these services. In this case Arkansas Division of Medical Services pays for the health services in stead of an insurance company, as is the case for patients not eligible for Medicaid. In this case as well as in the case of the mechanical and the agricultural industry, the information functions. The MMIS resides on an IBM platform in the Plano, Texas, EDS Service Management Center. It processes 2,470 million instructions per second of processing power and 12,691 gigabytes of direct access storage. In addition to the Tandem and IBM platforms, EDS supports a decision support system in Little Rock, Arkansas, using the UNIX® operating system on a Sun ${ }^{\mathrm{TM}}$ platform.

\subsection{Business Impact of the AEVCS system}

By implementing the AEVCS system, paper bills, checks, envelopes or postage stamps were eliminated. All 
status information e.g. payments, had to be accessed using the web site.

In 1998, Arkansas Governor Mike Huckabee noted that the state "saved about $\$ 30$ million in Medicaid costs as a result of the efficiency built into the system." That's a 17-month total drawn from achievements like the following. Governor Huckabee continues:

"Emergency room use by Medicaid patients dropped 60 percent -- falling to 10 percent below the general population. Average claims processing time was reduced from 15 to 3.5 days. Collection expense, a fact of life for many care providers, is practically "zero" on Medicaid claims. The AEVCS system dropped costly claim denials from 12 percent to 1 percent of the Medicaid outpatient caseload of a large children's hospital. Before EDS initiated a decision support system, programmers developed 130 reports from the database in a one-year period. After system installation, staff members generated reports at an annual rate of 1,140. That's well over an eight-fold increase."

An other significant impact according to Ray Hanley, Director, Medical Services for Arkansas Medicaid, of the AEVCS system was that "With AEVCS, we went from an error-prone paper claim system that took weeks or months to process a claim to an average turnaround time today of 3.8 days with an extremely high degree of accuracy".

Also, denied claims have fallen from 33 percent to less than 4 percent because the new system instantly flags errors for providers. Providers all over the state are gladly accepting Medicaid patients, which has improved both the access and quality of health care across the state.

Alone in savings of postage fees that went with the old paper eligibility card system, the state saved $\$ 60,000$ per month.

\section{Discussion of the Medical Services Case}

To argue for the relevance and applicability of the DKM model to health care administration, we intend to trace the knowledge management aspects in the case, including knowledge creation and sharing.

In the case of the Arkansas Division of Medical Services, the product state model serves the purpose of containing pertinent data about patients, providers and claims. These data are translated in the Medicaid Management Information System into valuable information to save the State of Arkansas's money and provide adequate, cost-effective health care to Medicaid beneficiaries. The information acquired in a well-specified context is knowledge that becomes a platform for action.
The health care administration case was presented in terms of business model that require a distributed knowledge management based on product state models. Our interpretation of the case bridges the two worlds: the Medicaid systems already developed and operating, and our theoretical model of distributed knowledge management. Our interpretation structures the data in accord with the multiple organisations approach of DKM and traces the impact upon product state models, i.e. the Arkansas DMS, the physicians and the patients.

Finally, a distributed decision support can also be tracked. Firstly, data acquisition and sharing (AEVCS) generate up-to-date patient eligibility and medical history. Secondly, the recurrently acquired physicians' and other health service providers' patient treatment data are made available as timely eligibility data accessed on-line by the very same health service providers when visited by patients. The eligibility is the knowledge exploitation outcome of the PSM of the Arkansas DMS. The treatment offered patients is the knowledge exploitation outcome of providers' access to tracking patient medical and treatment history across different providers. Patient health care satisfaction reflects the patients' use of a primary care physician and procedure information, helping to ease access to relevant health service provision.

\section{Conclusion and Perspectives}

Knowledge management schemes based on symmetric incentives are rarely found in literature. The distributed knowledge model merges specific knowledge with knowledge from other actors into a decision support specific for each actor in the network in recognition of actor role differences.

Traditionally, knowledge management is conceived in a bilateral model where information acquisition is separated from information use in the sense that the acquisition is done without any conception of who will use the knowledge and when. In the distributed knowledge model, the acquisition takes place in a structure where the usage and user is known, as both the acquisition and the use of the specific information of each actor relies upon a network based exchange with other actors. In this model symmetric incentives ensure sustainable knowledge acquisition and use emphasising the robustness of the model. The idea of a network of repositories each exchanging partial, specific knowledge giving and gaining value when distributed in the network is substituted for a common organisation-wide knowledge repository. 
The strength of a network distributed knowledge management system is the push forward of relevant knowledge to decision makers on a recurrent scheme, making economising on critical resources a strategic option. On option necessary to consider also in the framework of health care administrative cost drivers. Concurrent enhancement of the quality of health service at diminishing costs vouch for benefits shared by payers, patients and health care personnel.

\section{REFERENCES}

[1] Keen, P. G.W. Competing in Time. Ballinger Publ. 1986

[2] Sampler, J. L., Redefining Industry Structure for the Information Age. Strategic Management Journal 19. 343355. 1998.

[3] Hammer, M. and Champy, J., Reengineering the Corporation - A Manifesto for Business Revolution. Harper Collins Publishers, New York. 1993.

[4] Venkatraman, N., IT-Enabled Business Transformation: From Automation to Business Scope Redefinition. Sloan Management Review, 35, Winter 73-87. 1994.

[5] Hammer, M., Beyond Reengineering. Harper Collins Publishers. N.Y. 1996.

[6] Hax, A. and Wilde II, D.L. A Delta Model: Adaptive Management for a Changing World. Sloan Management Review 40 (2) 11-28. 1999.

[7] Konsynski, B.R., Strategic Control in the Extended Enterprise. IBM Systems Journal, 32(1), 111-142. 1993.

[8] Venkatraman, N. and Henderson, J.C. Real Strategies for Virtual Organizing. Sloan Management Review, 40 (1) Fall, 33-48. 1998.

[9] Choudhury, V. and Sampler, J. L., Information Specificity and Environmental Scanning: An Economic Perspective. MIS Quarterly, March 21(1) 25-53. 1997.

[10] Sridhar, S. Decision Support using the Intranet. Decision Support Systems, 23, 19-28. 1998.

[11] Pedersen, M.Kühn, A Theory of Informations. The Business Cycle Model. Copenhagen. Samfundslitteratur. 1996.

[12] Alstyne, M. van, The State of Network Organization: A Survey in Three Frameworks. Journal of Organizational Computing and Electronic Commerce. 7,2\&3) 83-151. 1997.

[13] Davenport, T. and Prusak, L., Working Knowledge - How Organizations Manage What They Know. Harvard Business School Press, Boston, MA. 1998.

[14] Scott, J. E., Organizational Knowledge and the Intranet. Decision Support Systems. 23, 3-17. 1998.

[15] Kotler, P., Marketing Management: Analysis, Planning, Implementation and Control. Prentice Hall. 1994.

[16] Nonaka, I., A Dynamic Theory of Organizational Knowledge Creation. Organization Science, 5, 14-37. 1994.
[17] Nonaka, I. and Byosiere, P. \& Borucki, C.C. \& Konno, N., Organizational Knowledge Creation Theory: A First Comprehensive Test. International Business Review. Special Issue on Knowledge in Organizations, Knowledge Transfer, and Cooperative Strategies. 3/4, 337-351. 1994.

[18] Nonaka, I. and Takeuchi, H., The Knowledge Creating Company - How Japanese Companies Create the Dynamics of Innovation. Oxford University Press. 1995.

[19] El Sawy, O.A. and Bowles, G., Redesigning the Customer Support Process for the Electronic Economy: Insights from Storage Dimensions. MIS Quarterly December 457-483. 1997.

[20] Favela, J. Capture and Dissemination of Specialized Knowledge in Network Organizations. Journal of Organizational Computing and Electronic Commerce 7 (2and3) 201-226. 1997.

[21] Davenport, T.H. and Klahr, P., Managing Customer Support Knowledge, California Management Review 40(3) 195-208. 1998.

[22] Pedersen, M.Kühn, Professional business service innovation: A distributed knowledge approach. Proceedings, CISTEMA Conference, Mobilizing Knowledge in Technology Management. October 24-27, 1999. Copenhagen Business School, 2 vols. 478-501. 1999.

[23] Polanyi, M., Personal Knowledge: Towards a Post-critical Philosophy. University of Chicago Press, New York. 1962.

[24] Polanyi, M., The Tacit Dimension. Anchor Day, New York. 1966.

[25] Spender, J.C., Organizational Knowledge, Learning and Memory: Three Concepts in Search of a Theory. Journal of Organizational Change Management, 9, 63-78. 1996.

[26] Hagel, J. and Rayport, J., The Coming Battle for Customer Information. Harvard Business Review, January-February, 53-65. 1997.

[27] Anderson, E.; Day, G.; Rangan, V.K. Strategic Channel Design. Sloan Management Review, June. 59-69. 1997.

[28] Krogh, G. von and Roos, J. Managing Knowledge Perspectives on Cooperation and Competition. Sage, London. 1996.

[29] Krogh, G. von and Nonaka, I. and Ichijo, K., Development Knowledge Activists. European Management Journal, 15(5), 475-483. 1997.

[30] Krogh, G. von, Roos, J. and Kleine, D. Knowing in firms Understanding, Managing and Measuring Knowledge. Sage, London. 1998.

[31] Davenport, T.H. and De Long, D.W. and Beers, M.C., Successful Knowledge Management Projects. Sloan Management Review. 39(2) Winter, 43-57. 1998.

[32] Ruggles, R., The State of the Notion: Knowledge Management in Practice. California Management Review. 40(3), 80-89. 1998.

[33] Alavi, M. and Leidner, D. E., Knowledge Management Systems: Issues, Challenges, and Benefits. Communications of the Association for Information Systems. Vol. 1, Paper 5, January. 1999. 
[34] El Sawy, O.A. and Pauchant, T.C., Triggers, Templates and Twitches in the Tracking of Emerging Strategic Issues. Strategic Management Journal 9 (5) 455-473. 1988.

[35] Strader, T. J.; Fu-Ren Lin; Shaw, M.J. Information Infrastructure for electronic virtual organization management. Decision Support Systems 23, 75-94. 1998.

[36] Callon, M., Techno-economic networks and irreversibility. In J. Law,ed. A Sociology of Monsters. Essays on Power, Technology and Domination. Sociological Review Monograph 38. London: Routledge. 1991.

[37] Law, J. and J. Hassard, Actor Network Theory and After. Blackwell. 1999.

[38] Hull, R.,V. Walsh, Green, K., and McMeekin, A. The Techno-Economic: Perspectives for Analysis and Intervention. Journal of Technology Transfer, 24. 185-195. 1999.

[39] Porter, M. E., The Competitive Advantage of Nations. Macmillan, N.Y. 1990.

[40] Porter, M.E. Clusters and the New Economics of Competition. Harvard Business Review. NovemberDecember 76(6) 77-90. 1998a.

[41] Porter, M.E. The Adam Smith Adress: Location, Clusters, and the "New" Microeconomics of Competition. Business Economics. Washington, January 33(1) 7-13. 1998 b.

[42] Wernerfelt, B. A Resource-based view of the firm. Strategic Management Journal 5, 171-180. 1984.

[43] Milgrom, P. and J. Roberts, Economics, Organization and Management. Englewood Cliffs, N.J. Prentice-Hall International, Inc. 1992.

[44] Foss, N. J. (ed.), The Resource-based Perspective on the Firm. London: Routledge Kegan Paul. 1997.

[45] Williamson, O. E., The Economic Institutions of Capitalism. New York: The Free Press. 1985.

[46] Williamson, O. E., Economic Organization. Brighton: Wheatsheaf Books Ltd. 1986.

[47] Williamson, O. E., Transaction cost economics and organization theory. In Smelser, N.J. and Swedberg,R. (eds) The Handbook of Economic Sociology. Princeton U P. 77-107. 1994.

[48] Larsen, M.H.; L.R. Franck, and Pedersen, M. Kühn. Frontline CALS - Extranet Enabled Support of Customer Relations Based on Product State Information. Proceedings of the 7th European Conference on Information Systems. Copenhagen, June, 302-319. 1999.

[49] Huber, G., Organizational Information Systems: Determinants of Their Performance and Behavior. Management Science 28 (2) February. 138-155. 1982.

[50] Stalk, G. and Hout, T.M. Competing Against Time. N.Y. The Free Press. 1990.

[51] Wang, E. T.G. and Barron, T. Computing services supply management: Incentives, information, and communication. Decision Support Systems 19, 123-148. 1997.

[52] Badaracco, Jr. Joseph L., The Knowledge Link. Harvard Business School Press. Boston, Mass. 1991.

[53] Teece, D. J., Profiting from technological innovations: Implications for integration, collaboration, licensing and public policy. in Teece, D.J. Ed., The Competitive Challenge. Cambridge. Mass. 1987.

[54] Chesbrough, H.W. and Teece, D. J. When is Virtual Virtuous? Organizing for Innovation. Harvard Business Review, 74, Jan-Feb. 65-73. 1996.

[55] Johanson, J. and Mattsson, L.-G. Interorganizational relations in industrial systems: a network approach compared with the transaction-cost approach. International Studies of Management and Organization. 17. 34-48. 1987.

[56] Galbraith, J.R. and Lawler III, E.E., Organising for the Future. The New Logic for Managing Complex Organizations. San Francisco: Jossey-Bass Publishers. 1993.

[57] Ghosh, A. K., E-Commerce Security. Weak Links, Best Defenses. Wiley Computer Publ. N.Y. 1998.

[58] Riempp, G. and Nastansky, L., From Islands to Flexible Business Process Networks- Enabling the Interaction of Distributed Workflow Management Systems. Proceedings of the 5th European Conference on Information Systems.Vol. 1, 481-496. 1997.

[59] Medicaid . http://www.medicaid.state.ar.us/index.htm. 1999

[60] EDS.

http://www.eds.com/case_studies/arkansas/cs_ak_si.shtml . 1999 